\title{
TOWARDS A FRAMEWORK FOR HEALTHCARE SIMULATION
}

\author{
Tillal Eldabi \\ Terry Young \\ School of Information System, Computing and Mathematics \\ Brunel University, Uxbridge \\ Middx, UB8 3PH United Kingdom
}

\begin{abstract}
The changing needs of healthcare provision around the world are forcing service designers and decision makers to adopt new tools in design and evaluation of processes. Apart from the pressure to deliver better services from constrained resources, the increasing use of metrics to monitor and manage care delivery, also means that service providers require a clearer idea of how a service improvement will perform prior to implementation. In turn, this opens up an opportunity for a much greater use of simulation and modeling techniques, provided they can be set within an appropriate framework. This paper discusses and describes a research project aimed at conducting pilot work for developing a framework that facilitates joined up thinking and enables integrative modeling. An approach to achieving such an end is described and progress to date is reported. Since this is an ongoing project, some of the latest results are presented at the conference.
\end{abstract}

\section{INTRODUCTION}

Healthcare delivery systems around the world face increased pressure on a number of fronts. Populations are evolving both in terms of their demographics and expectations, with the result that better services must be provided to more people on a more uniform basis than ever before. Moreover, while cost containment is an issue today, the reduction of the workforce as the population ages is certain to require that all these improvements are eventually delivered using proportionately fewer staff in future.

In this paper, we focus on three critical trends significantly associated with this pressure, and use these to scope and sculpt a requirement for simulation and modeling techniques. The first of these is the way in which the appeal to industrial process thinking is re-conceptualizing medicine in terms of services, which must be designed, launched, monitored and continuously improved. As we shall see, while the appeal to industrial processes is itself a way of addressing the pressure to deliver more for less (and in a more uniform manner), it also creates a need for tools that can be used to design processes, set appropriate metrics, and provide a common viewpoint around which disparate communities may gather to review and continuously develop the service.

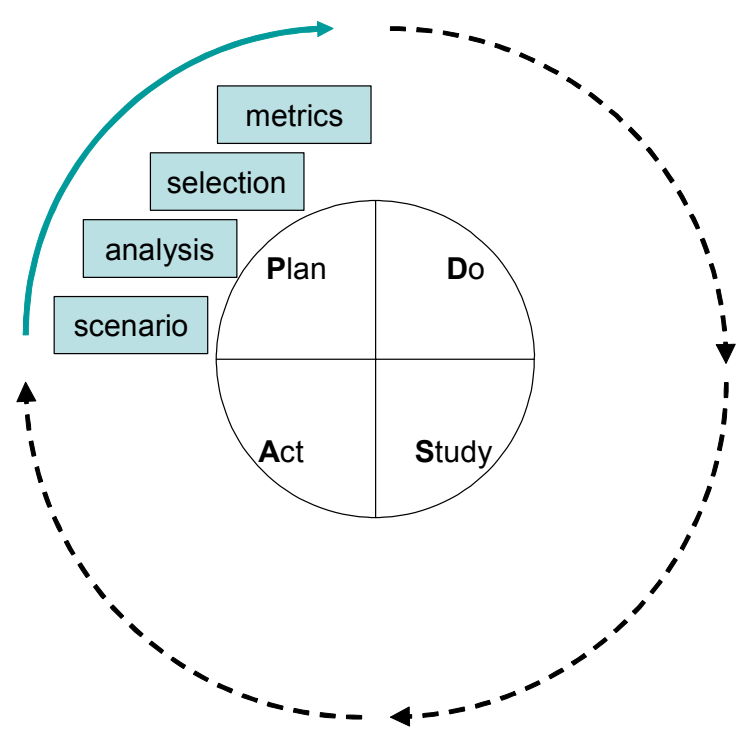

Figure 1: PDSA Cycle

A second set of pressures concern the roles of drugs and technology in care delivery. Again, as we shall see, while individual pharmaceuticals and technologies tend to become cheaper and more effective with time, the great profusion of them, and the heightened expectations they create in the community at large, generate considerable budgetary pressures. Moreover, unless it is possible to articulate how extra spend in these areas can be clearly converted into savings in the time of overstretched staff, it is impossible to realize the compensations that medical drugs and devices have to offer. A further observation, is that, by helping to prolong life (for instance through implantable pacemakers), the technologists and pharmacists create yet more demand for health services as populations that would have died early survive into old age and experience the diseases and burdens associated with ageing. This is coupled by the lack of consistency of adoption, which can be a 


\section{Eldabi and Young}

source of inequality sometimes (House of Commons Health Committee 2005).

Finally, as the cost of healthcare provision - which exceeds \$3 Trillion annually worldwide - continues to rise, governments are inevitably drawn in. Allied to the pressure to streamline provision, this creates a need to be able to integrate services, both with one another and also with top-level policy. This manifests itself in many ways - one of the more extreme forms being in the UK where the government is trying to manage the whole system through a set of national performance measures. A current example is the '18 week wait' which will start the clock ticking when a patient first presents as a primary care patient and must be stopped less than 18 weeks later with the appropriate intervention or treatment (18 Weeks Delivery Programme 2006).

These trends are forcing the care delivery community to find new ways to design services, evaluate their performance, and then to link them to one another, while being able to assess their implications at other scales and levels. The fact that simulation and modeling provides an obvious and effective means of doing this, is opening up a resurgence of interest in simulation and modeling as an important tool when improving healthcare delivery.

The challenge lies in bringing people, processes and technology together in an integrated fashion to plan, develop, and roll-out better services. In this paper we describes a collaborative research project as our attempt to develop a framework that enables modeling and simulation, as system-level techniques, to link the different elements of care delivery and support implementation at all levels.

\section{BACKGROUND}

Innovation in healthcare delivery presents a number of interesting socio-technological problem (Kaplan 2001). An example of this would be the NHS' Connecting for Health project to renew the national IT infrastructure (see Connecting for Health (2006)) which may cost as much as $£ 20$ Billion (Comptroller and Auditor General 2006), and which is also facing difficulties in terms of uptake and adoption (Hendy et al. 2005; Lister and Charter 2005). The same is true for medical devices (House of Commons Health Committee 2005; Healthcare Industries Task Force 2004). In the US, the Institute for Health Improvement has led much of the thinking around improvement of healthcare delivery and has focused on process (Berwick 1998; Spear 2005).

This approach tends to emphasize the 'fit' of ICT and devices (Kaplan 2001; Hendy et al. 2005; Heeks, Mundy, and Salazar 1999). An alternative view is that technology, especially ICT, is transformational and drives change (Connecting for Health 2005). The Modernisation Agency (1998-2005) established PDSA cycles as the NHS' innovation methodology as part of a wider appeal to industrial methods (NHS Modernisation Agency 2002; NHS 2003; Young et al. 2004) (see Figure 1). In the 'Plan' phase, a multidisciplinary team assesses options around a given improvement scenario and selects a trial improvement together with metrics for later assessment. This is then implemented as an experiment 'Do' and evaluated 'Study' before being adopted or discarded 'Act'. Technology can be addressed, but only if the team has experience of that technology.

While healthcare modeling and simulation has played an important role in service design and evaluation (see Royston (1999); Jun, Jacobson, and Swisher (1999); Fone et al. (2003); Brailsford and Harper (2007)), the current needs create an opportunity to develop a more systematic way of using such tools, by which we refer to risk-free worlds in which to explore reality, usually but not necessarily involving computers. This is a much broader definition than many experts in the field might accept. Such approach might overcome the limitations of a team's experience and support more elements of planning (as shown by the dotted arrows in Figure 1).

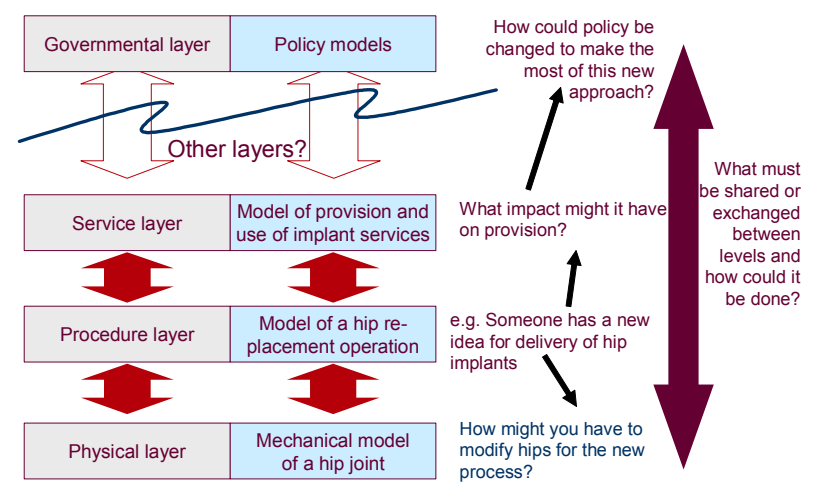

Figure 2: Example of multi-layered simulation needs

We note, therefore, that a more systematic application of healthcare modeling and simulation has the potential to address two of the critical trends raised at the start. Firstly, simulation provides a design methodology for service development that integrates technology with process and that also provides a means of assessing the value of different technologies. This is critical as resources are increasingly stretched, and it becomes ever more important to make cost-effective choices in terms of design and delivery. Secondly, it provides a means of linking industrial process thinking to healthcare improvement methods in a way that aligns with on-the-ground practice.

Turning to the third trend cited in the introduction, we note that a critical problem lies in the unexpected impact that changes in one part of a system may have on other areas. Moreover, in order to convert best local practice into national policy, one must understand the impact that changes at one level will have on other levels. 


\section{Eldabi and Young}

As an illustration, consider the provision of orthopedic implants. Figure 2 shows how a new procedure for hip surgery raises questions at the device, service and policy levels. Clearly, there are modeling tools that could be used at every level, but there is no systematic way of selecting the best tool, and crucially, there is no means of connecting up tools to understand what impact changes at one layer might have on the rest of the system.

\section{A MULTIDIMENSIONAL FRAMEWORK FOR HEALTHCARE SIMULATION}

One of the means of putting such modeling tools on a more structured footing is to develop a framework. This would enable these methods or tools to be connected and across different levels, from mechanical design through services design, to the policy level. Figure 2 adopts an "armedforces synthetic environments" approach in which to frame the implants example (Beckett 2000). We note that the type of model varies with the 'level' - policy models tend to be normative and statistical (large-scale gaming without simulation may be also used (Office of Public Management 2004). At the bottom level, specific procedures, interventions, or devices (such as artificial hips) are amenable to deterministic models (such as finite elements in Berkley et al. (1999) or even mechanical simulations as in Barnett et al. (2002).

In terms of the availability of models, we note that there are a range of tools available for the central layers (Royston 1999; Jun, Jacobson, and Swisher 1999; Fone et al. 2003; Brailsford and Harper 2007; Lehany and Paul 1996; Brailsford and Schmidt 2002; Brailsford et al. 2004; Taylor, McClean, and Millard 2000; Smith, Nugent, and McClean 2003; Connell 2001; Eldabi, Paul, and Taylor 2000; Eldabi, Irani, and Paul 2002; Young 2005; Royston et al. 1999), including "soft" models and conceptual approaches (Lehany and Paul 1996; Connell 2001). However, most of the work to date has focused on some bounded aspects of healthcare (e.g. the preponderance of hospital work reported in Fone et al. (2003)) and much has been opportunistic in terms of pairing simulation experts with clinicians.

In terms of integrating methods together, some initial success has, for instance, involved linking process and behavioral models in Brailsford and Schmidt (2002) and a recent survey by Eldabi, Paul, and Young (2007) indicates that prominent researchers are seeking ways of fitting elements of this field together in some overarching way.

How feasible is it to consider such overarching frameworks? In IT, the Zachman framework featured in Zachman (1987) is an enterprise-scale layered ICT structure that might overlap conceptually with part of Figure 1, and which parses each layer in six dimensions (who, why, how, etc). Another attempt to provide some structure, this time specifically related to healthcare, is provided by IBM, which places simulation alongside factors associated with business, technology and delivery (IBM Business Consulting Services 2004). Critically, this recognizes that a framework must connect to industrial process methodologies, a link explored by Young et al. (2004), which notes that these methods require adaptation for healthcare, because (unlike components) patients are responsive and increasingly keen to exercise meaningful and informed choice.

Clearly, constructing a framework will involve more than making critical connection or finding ways to combine simulation and modeling methods in order to offer a more complete solution. Firstly, there will be some significant barriers, especially in terms of intrinsic incompatibilities. For instance, we note that this approach adopts an engineering stance to the extent that it seeks to identify improvement and to link it back to the design of the technology or the service. However, the IS literature embraces both clear cut views of success and failure, such as in Littlejohns, Wyatt, and Garvican (2003), as well as more participative and subjective perspectives (Mumford 1983; Wilson and Howcroft 2002). Moreover there is no guarantee that the corpuses of literature, for instance of engineering, operational research, and operations management, will converge sufficiently to enable the development of a useful framework.

In this paper we describe a feasibility study for developing such a framework. The study is conducted by of way collaboration of four UK universities to assess the viability of constructing such a framework and its effectiveness in facilitating a joined up approach to modeling.

\section{METHODOLOGY}

To overcome the above mentioned barriers, we have adapted and built on a methodology proposed by Clarkson (2005) that starts with an exploration of diverse disciplinary corpuses, while ensuring that the findings can be fused into useful taxonomies. The aim is that these will eventually enable a full framework to be developed. However, at this stage, the goal is developing a framework selection tool that will enable healthcare professionals to scope the decisions they must make in designing services and then make appropriate selections of modeling tools. The timeline down the left of Figure 3 relates to an ongoing project which began in April 2007, and is called RIGHT. The aim is to update this written submission with some of the findings from the literature surveys. 


\section{Eldabi and Young}

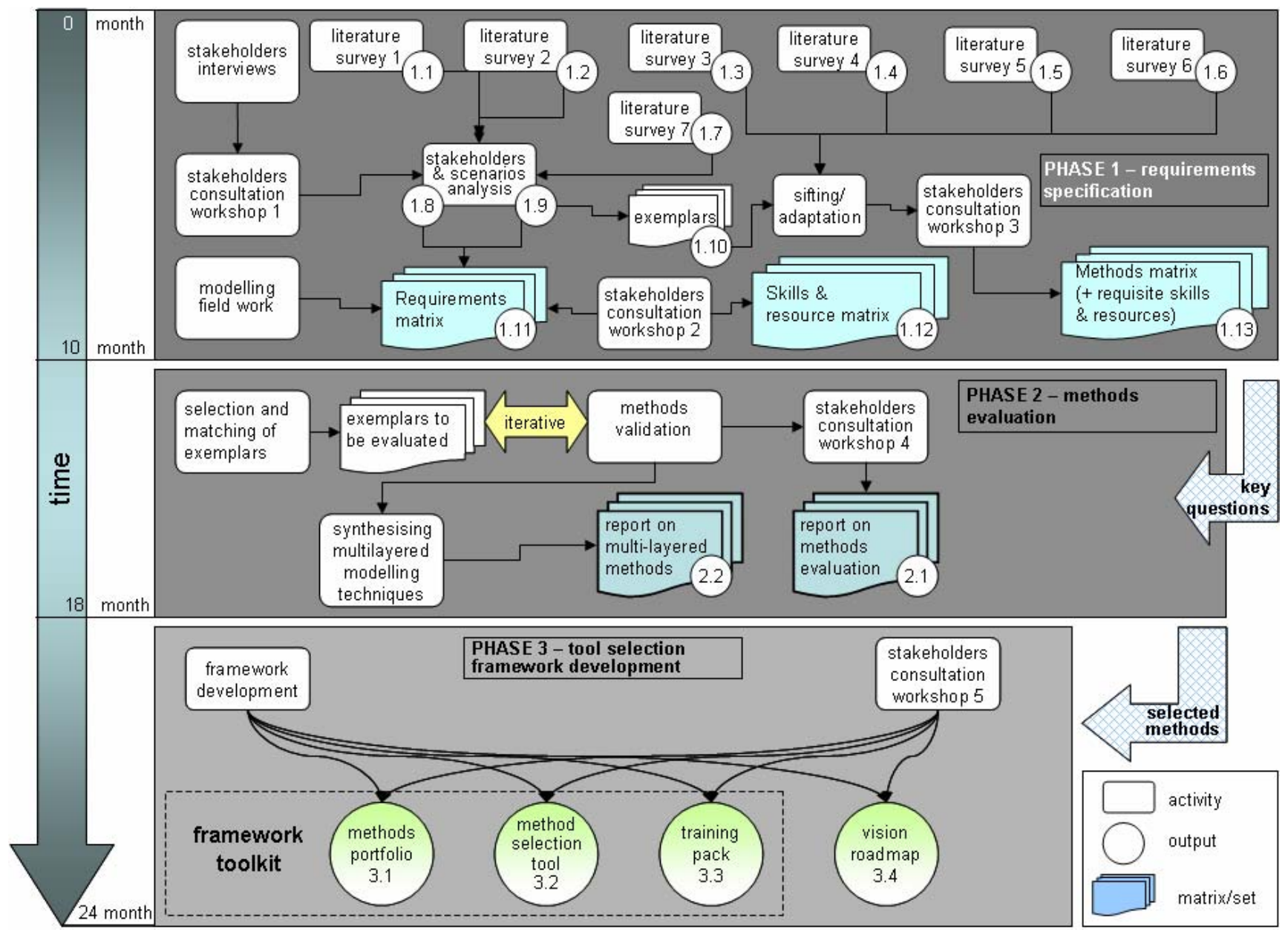

Figure 3. The RIGHT framework development methodology

A key element of this approach is the early construction of three matrices:

1) Requirements Matrix: This will provide a classification of modeling and simulation requirements in healthcare, together with the critical measures by which success can be assessed. It will focus on the nature of solutions that people require and will classify these requirements by healthcare professionals. For instance, healthcare managers are likely to be asking different questions, as compared to clinicians and may therefore have different requirements.

2) Skills \& Resources Matrix. This will capture the current capability within the healthcare system (in terms of techniques and approaches that are used or bought-in through consultancy services) as well as the current and projected needs in terms of required skills and resources for the modeling of different healthcare scenarios. The resources issue will be broadly interpreted to include access to data, the type of data available, financial resources to hire in help, education re- sources in terms of the skills within a team, and the time available to address a given design problem.

3) Methods Matrix. This will provide a complete description of modeling and simulation methods, together with their requisite skills \& resources.

The term "matrix" here represents a multidimensional structure, which captures all the pertinent aspects of the subjects and describes their interrelationships. A matrix should be complete and expandable, in the sense that any situation or scenario can be completely defined using the matrix structure. The development of these matrices is being informed in two ways, firstly by literature review and secondly by stakeholder engagement. The literature reviews have been selected to cover a broad area:

- Review of stakeholder analysis methods;

- Survey of previous work in framework development;

- Review of modeling \& simulation methods in healthcare; 


\section{Eldabi and Young}

- Review of modeling \& simulation methods in aerospace and the military;

- Review of modeling \& simulation methods in industry and manufacturing;

- Review of management and planning methods in industry and manufacturing;

- Review of management and planning methods in healthcare.

The review documents, together with a series of documents developed from the consultative workshops, will be analyzed to develop the matrices. The next phase is experimental through a set of stretching, multi-agency, exemplars. A selection of currently agreed exemplars is given in Table 1 below. These range from national to regional to local service design problems. They will enable the research teams to undertake field work both to understand how and what modeling works best, but also to see how the problems are articulate for the modeling and what responses through simulation are most appropriate.

The final phase of the program will require the synthesis of the desk and field research into a framework selection tool as shown, with a reference work on modeling methods and accessible embodiments of those methods, a selection tool, together with supporting training material. The final piece is to develop a roadmap to share with the wider community about the viability of an overall framework and an initial estimate of the time and resources required to produce it and to develop a truly useful set of tools for the healthcare service design community.

\section{EARLY FINDINGS}

Work on this project is now underway as a core collaboration between the following universities in the UK: Brunel, Cambridge, Southampton and Ulster. Although in the early stages, this project has thrown up significant challenges. It took about three years to build the team and win the grant, so although the team must move rapidly through the phases described, it does so not entirely from a standing start.

One of the most interesting elements of the early phase activity lies in working quickly while covering the fields broadly. Many of the literature reviews have target corpuses of papers numbering a few thousand (at least one of over 10,000). For such a wide range of reviews to be undertaken on a period of time that enables them usefully to feed into the matrix development, creates a need for developing review methods that combine a degree of rigor with speed and scope. Key results will be presented at the conference.
Table 1: A selected list of Exemplars

\begin{tabular}{|c|c|}
\hline Scenarios & Exemplar Description \\
\hline $\begin{array}{l}\text { Ambulance } \\
\& \text { Emer- } \\
\text { gency Care }\end{array}$ & $\begin{array}{l}\text { Complex referral pathways: Developing } \\
\text { models to address complex referral path- } \\
\text { ways by way of understanding the structure } \\
\text { and causes of delays. }\end{array}$ \\
\hline $\begin{array}{l}\text { Chronic } \\
\text { Disease } \\
\text { Manage- } \\
\text { ment }\end{array}$ & $\begin{array}{l}\text { Technology infrastructure for closer to } \\
\text { homes delivery: Assessing how whole sys- } \\
\text { tems technology infrastructure can be de- } \\
\text { ployed to support the management of } \\
\text { Chronic Diseases closer to patients' homes. } \\
\text { Costs justification of Infrastructure deploy- } \\
\text { ment by appropriate business cases to ex- } \\
\text { plore and decide option appraisals. }\end{array}$ \\
\hline $\begin{array}{l}\text { Cross- } \\
\text { Organiza- } \\
\text { tional }\end{array}$ & $\begin{array}{l}\text { Managing the complexity of multi- } \\
\text { organizational care delivery: This exem- } \\
\text { plar will look at the use of modeling within } \\
\text { and between organizational levels, and in- } \\
\text { formation from the model could help inte- } \\
\text { grate around } 30 \text { different organizations aim- } \\
\text { ing at delivering efficient Emergency care. }\end{array}$ \\
\hline $\begin{array}{l}\text { Practice- } \\
\text { based } \\
\text { Commis- } \\
\text { sioning }\end{array}$ & $\begin{array}{l}\text { Analysis of complex demand and access } \\
\text { pathways to operate the new commission- } \\
\text { ing paradigm: Modeling the supply chain } \\
\text { of Emergency delivery and assessing best } \\
\text { combination of resource and capacity to } \\
\text { meet demands given current changes. }\end{array}$ \\
\hline $\begin{array}{l}\text { Outpatient } \\
\text { Services }\end{array}$ & $\begin{array}{l}\text { Managing patient "choice" and resources } \\
\text { utilization: This exemplar is looking at } \\
\text { managing patient "choice". Currently, the } \\
\text { processes of running clinics are unrespon- } \\
\text { sive to clinical and managerial control and } \\
\text { little is learnt from mistakes. Results are } \\
\text { variably effective, so the exemplar should } \\
\text { enable stakeholders to identify better ways } \\
\text { to handle the system }\end{array}$ \\
\hline $\begin{array}{l}\text { Policy Plan- } \\
\text { ning }\end{array}$ & $\begin{array}{l}\text { The impact of changes in policy and eli- } \\
\text { gibility for specialists: Looking at the use } \\
\text { of modeling as one tool to help explore key } \\
\text { strategic themes related to workforce plan- } \\
\text { ning to meet healthcare needs in a competi- } \\
\text { tive and shrinking workforce market - both } \\
\text { at local and national levels - with senior } \\
\text { managers responsible for either the com- } \\
\text { missioning or provision of services. }\end{array}$ \\
\hline
\end{tabular}

\section{CONCLUSIONS}

A number of constraints in delivering healthcare services appear to be renewing interest in methods for designing services and evaluating their performance ahead of deployment. Simulation and modeling have an important 


\section{Eldabi and Young}

role to play, and the authors describe an ongoing program to classify a wide range of simulation and modeling techniques against healthcare needs and requirements. Work is progressing towards the development of a framework selection tool that will enable healthcare service designers to evaluate their needs and select appropriate tools. This project is progressing rapidly, and a selection of key results will be presented at the conference.

\section{REFERENCES}

18 Weeks Delivery Programme. 2006. Available via <http://www.18weeks.nhs.uk/public/defau lt.aspx $>$ [accessed March 11, 2007].

Barnett, P. I., H. M. J. McEwen, D. D. Auger, M. H. Stone, E. Ingham, and J. Fisher. 2002. Investigation of wear of knee prostheses in a new displacement/force-controlled simulator. In Proceeding of Institution of Mechanical Engineering, Part H, Journal of Engineering in Medicine 216:51-61.

Beckett P. 2000. Wargames. Aerospace International 2000:12-15.

Berkley J., S. Weghorst, H. Gladstone, G. Raugi, D. Berg, M. Ganter. 1999. Fast finite element modelling for surgical simulation. Studies in Health Technology and Informatics 62:55-61.

Berwick, D. M. 1998. Developing and testing changes in delivery of care. Annals of Internal medicine 128:651-656.

Brailsford, S. C. and P. R. Harper. 2007. Editorial of Special Issue: Operational Research in Health, Journal of the Operational Research Society, 58:141-144.

Brailsford, S. C., V. A. Lattimer, P. Tarnaras, and J. C. Turnbull. 2004. Emergency and on-demand health care: modelling a large complex system. Journal of the Operational Research Society 55:34-42.

Brailsford, S. and B. Schmidt. 2002. Towards incorporating human behaviour in models of health care systems: An approach using discrete event simulation. European Journal of Operational Research 150:1931.

Clarkson, P. J. 2005. Prospective hazard analysis: tailoring prospective methods to a healthcare context. Unpublished Tender for the Department of Health PSRP (Reference Number: PS/035). University of Cambridge, UK.

Comptroller and Auditor General. 2006. Department of Health: The National Programme for IT in the NHS. National Audit Office HC 1173.

Connecting for Health. 2005. NHS: the benefits of computer technology can only be realised when systems of work are changed. Available via <http://www.connectingforhealth.nhs.uk/ worldview/protti6/> [accessed March 1, 2006].
Connecting for Health. 2006. Available via <http://www. connectingforhealth.nhs.uk/ $>$ [accessed March 1 2006].

Connell, N. A. D. 2001. Evaluating soft OR: some reflections on an "unsuccessful" implementation using an SSM-based approach. Journal of the Operational Research Society. 52: 150-160.

Eldabi, T, Z. Irani, and R. J. Paul. 2002. A proposed approach for modelling health-care systems for understanding. Journal of Management in Medicine. 16:170-187.

Eldabi, T., R. J. Paul, and S. J. Taylor. 2000. Simulating economic factors in adjuvant breast cancer treatment. Journal of the Operational Research Society, $51: 465-475$.

Eldabi, T., R. J. Paul, and T. Young. 2007. Simulation modelling in healthcare: reviewing legacies and investigating futures. Journal of the Operational Research Society 58:262-270.

Fone, D., S. Hollinghurst, M. Temple, A. Round, N. Lester, A. Weightman, K. Roberts, E. Coyle, G. Bevan, and S. Palmer. 2003. Systematic review of the use and value of computer simulation modelling in population health and healthcare delivery. Journal of Public Health Medicine 25:325-335.

Healthcare Industries Task Force. 2004. Better healthcare through partnership: a programme for action. Department of Health. Available via <http://www.advisorybodies.doh.gov.uk/h itf/index.htm> [accessed November 19, 2004].

Heeks, R., D. Mundy, and A. Salazar. 1999. Why health care information systems succeed or fail. Available via <http://wWw.sed.manchester.ac.uk/ idpm/publications/wp/igov/igov_wp09.htm $>$ [accessed January 31, 2005].

Hendy J., B. C. Reeves, N. Fulop, A. Hutchings, and C. Masseria. 2005. Challenges to implementing the national programme for information technology (NPfIT): a qualitative study. BMJ 331:331-336.

House of Commons Health Committee. 2005. The use of new medical technologies within the NHS. Fifth report of session 2004-2005, Volume II: Written and Oral Evidence, $p$ Ev3. available via <http://www.publications.parliament.uk/ $\mathrm{pa} / \mathrm{cm} 200405 / \mathrm{cmselect/cmhealth/398/398ii}$ . pdf > [accessed March 1, 2006].

IBM Business Consulting Services. 2004. The safe and lean provider for the healthcare industry: clinical and business process optimization. (IBM White Paper). Available via <http://www.ibm.com/ industries/healthcare/doc/content/bin/ Safe_and_lean.pdf> [accessed November 10, 2004].

Jun, J. B., S. H. Jacobson, and J. R. Swisher. 1999. Application of discrete-event Simulation in health care and 


\section{Eldabi and Young}

clinics: A survey. Journal of the Operational Research Society 50:109-123.

Kaplan B. 2001. Evaluating informatics applications some alternative approaches: theory, social interactionism and call for methodological pluralism. International Journal of Medical Informatics 64:39-56.

Lehany, B. and R. J. Paul. 1996. The use of soft systems methodology in the development of a simulation of outpatient services. Journal of the Operational Research Society 47:864-870.

Lister S. and D. Charter. 2005. The doctor won't see you now. The Times, January $19 \mathrm{p} \mathrm{3.} \mathrm{Available} \mathrm{via}$ $<$ http://www.timesonline.co.uk/article/0 , ,2-1446775,00.html> [accessed March 1, 2005].

Littlejohns P., J. C. Wyatt, and L. Garvican. 2003. Evaluating computerised health information systems: hard lessons still to be learnt. BMJ 326:860-863.

Mumford, E. 1983. Designing participatively: A participative approach to computer systems design. Manchester Business School. UK.

NHS. 2003. Introduction to Lean Thinking. Available via <http://www.natpact.nhs.uk/demand_manag ement/wizards/big_wizard/index.

php?page=/demand management/wizards/big _wizard/Step_3/Introduction_to

lean_thinking.php> [accessed January, 19 2006].

NHS Modernisation Agency. 2002. NHS Improvement leader's guide to process mapping, analysis and redesign. Available via <www.modern.nhs.uk/ improvementguides/process> [accessed June 30, 2004].

Office of Public Management. 2004. Available via <http://www.opm.co.uk/HSC.html> [accessed December 22, 2004).

Royston, G. 1999. Commentary: trials versus models in appraising screening programmes. British Medical Journal 318:356-361.

Royston, G., A. Dost, J. Townshend, and H. Turner. 1999. Using system dynamics to help develop and implement policies and programmes in healthcare in England. System Dynamics Review 15:293-313.

Smith, A. E., C. D. Nugent, and S. I. McClean. 2003. Evaluation of inherent performance of intelligent medical decision support systems: utilising neural networks as an example. Artificial Intelligence in Medicine 27:1-27.

Spear, S. J. 2005. Fixing health care from the inside, today. Harvard Business Review 83:78-91.

Taylor, G. J., S. I. McClean, and P. H. Millard. 2000. Stochastic Models of Geriatric Patient Bed Occupancy Behaviour. Journal of the Royal Statistical Society (A) 163:39-48.

Wilson, M. and D. Howcroft. 2002. Re-conceptualising failure: social shaping meets IS research. European Journal of Information Systems. 11:236-250.
Young, T. P. 2005. An agenda for healthcare and information simulation. Health Care Management Science. 8:189-196.

Young, T. P., S. Brailsford, C. Connell, R. Davies, P. R. Harper, J. H. Klein. 2004. Using industrial processes to improve patient care. British Medical Journal 328: $162-164$.

Zachman, J. A. 1987. A Framework for Information Systems Architecture. IBM Systems Journal 26:276-292.

\section{ACKNOWLEDGEMENTS}

The authors acknowledge support for this work from the Engineering and Physical Sciences Research Council (award reference EP/E019900/1). Bringing the RIGHT project into being has been a team effort, with significant effort from each of the investigators, including the following, whom the authors cordially thank: Dr Sally Brailsford, Prof John Clarkson, Prof Con Connell, Prof Paul Harper, Dr Jonathan Klein, Prof Sally McClean, and Dr Lampros Stergioulas. They also thank Peter Taylor for his role in coordinating this complex and fast-moving project. Any views or opinions presented herein are those of the authors and do not necessarily represent those of RIGHT, its associates or its sponsors.

\section{AUTHOR BIOGRAPHIES}

TILLAL ELDABI is a lecturer at the School of Information Systems, Computing and Mathematics at Brunel University, UK. He received a B.Sc. in Econometrics and Social Statistics from the University of Khartoum. He received his M.Sc. in Simulation Modelling and his Ph.D. from Brunel University. His research is in aspects of healthcare management and the intervention of simulation and his main research also concentrates on the economy of healthcare delivery. He is looking to exploit the means of simulation on the wider information systems management area to assist in problem understanding. His email address is <tillal.eldabi@brunel.ac.uk>.

TERRY YOUNG is professor of Healthcare Systems at the School of Information Systems, Computing and Mathematics at Brunel University since 2001. He received a BSc in Electronic Engineering \& Physics and a $\mathrm{PhD}$ in high precision laser heterodyne spectrometry both form the University of Birmingham. Prior to joining Brunel University he spent over 16 years in industry in communications research and management for a range of applications which included healthcare. His current research interests centre around the delivery of healthcare and the role of technology in it. He is the Principal Investigator of the RIGHT project featured in the paper and a multimillion project (named MATCH) that looks into new product development in the medical device industry. His email address is <terry. youngebrunel. ac.uk>. 